\title{
KIDNEY FUNCTION IN ADRENAL INSUFFICIENCY ${ }^{1}$
}

\author{
BY CHRISTINE WATERHOUSE AND E. HENRY KEUTMANN \\ WITH THE TECHNICAL ASSISTANCE OF KATHRYN Y. CUSSON \\ (From the Department of Medicine, University of Rochester School of Medicine and Dentisiry, \\ and the Medical Clinic of Strong Memorial and Rochester Municipal \\ Hospitals, Rochester, N. Y.)
}

(Received for publication December 22, 1947)

An association between adrenal insufficiency and disturbed kidney function has been demonstrated repeatedly. The first report on renal failure in Addison's disease was that of Smith (1) in 1897. In 1942 Talbott et al. (2) reviewed the literature and reported studies on patients who had adrenal insufficiency but were not in crises. They found formation of glomerular filtrate to be reduced. After institution of treatment with desoxycorticosterone acetate, there was an increase in glomerular filtration of 32 per cent in five patients. However, the values obtained were still below normal. With diminished absorption from implanted pellets of desoxycorticosterone acetate the rate of formation of glomerular filtrate decreased again. Moderate reduction of renal plasma flow was observed also as well as slight reduction of the maximum capacity of the tubules for excreting diodrast.

In recent years renotrophic effects have been demonstrated after the administration of various steroid hormones to mammals, especially androgens $(3,4)$. Testosterone propionate was found to increase the maximal capacity of the kidney tubules to excrete diodrast in castrated female dogs (5). No increase of renal function could be demonstrated when the same hormone was given to normal men, a eunuchoid male, and patients with kidney disease $(6,7)$, even when the dose was as large as $300 \mathrm{mg}$. per diem. Nevertheless, since the renotrophic action is believed to affect mainly the tubular cells and since in some cases of Addison's disease atrophy of these cells has been described (8 to 10 ) it was thought advisable to observe the influence of hormone therapy on the kidney by means of the more refined tests of renal function which are now available.

\footnotetext{
1 The testosterone propionate and desoxycorticosterone acetate used in these studies were furnished by the Ciba Company.
}

\section{CLINICAL MATERIAL AND METHODS}

Thirteen patients were studied. None had evidence of any primary renal disorder. None had proteinuria or abnormal urinary sediments when not in crisis. Most of the clinical data pertinent to the investigations of this report are summarized in Table I.

In the group with Addison's disease, there were four men and five women. All gave typical histories, namely, weakness, languor, anorexia, loss of weight, nausea, and vomiting. All had been in crisis on one or more occasions. Physical examination of each showed the characteristic pigmentation of the skin and mucous membranes. All developed hypotension and nausea when not treated. In each case the shape of the sugar tolerance curve after 50 grams of glucose by mouth was flat, with hypoglycemia developing two to three hours after administration of the glucose. In several of the earlier cases chloride excretion tests (11) had been attempted but could not be completed because of impending crisis. The neutral 17ketosteroid excretion in the urine, done by the method of Talbot et al. (12), was decreased in all patients (Table I). Patient A. F. was found to have pulmonary tuberculosis which was considered quiescent after serial $\mathbf{x}$-ray studies. In none of the other patients was there evidence of tuberculosis.

Four patients, two men and two women, had pituitary insufficiency. That of the men (W. K. and A. B.) was the result of chromophobe adenomata. The women, R. F. and A. M., had no evidence of tumors; in both the beginning of the disease followed pregnancy. They had the typical appearance of "pituitary myxedema" as described by Means et al. (13). In each of these four patients the excretion of neutral 17-ketosteroids in the urine was reduced to very low levels. Chloride excretion tests, done according to the regime outlined by Cutler, Power, and Wilder (11), gave results characteristic of adrenal insufficiency. Oral sugar tolerance curves were flat and there was failure of the blood sugar to rise when hypoglycemia was produced with the insulin tolerance test of Fraser, Albright and Smith (14). This test was not done in the case of $\mathrm{A}$. M. because when she fasted for comparatively short periods her blood sugar frequently decreased to less than $50 \mathrm{mg}$. without tendency to rise unless carbohydrate was given.

A. B. revealed evidence by x-ray of a gradually expanding mass in the pituitary fossa since 1933. Definite symptoms of pituitary insufficiency had been present since 1935. Since 1940 he has gradually developed hyperten- 
RIDNEY FUNCTION IN ADRENAL INSUFFICIENCY

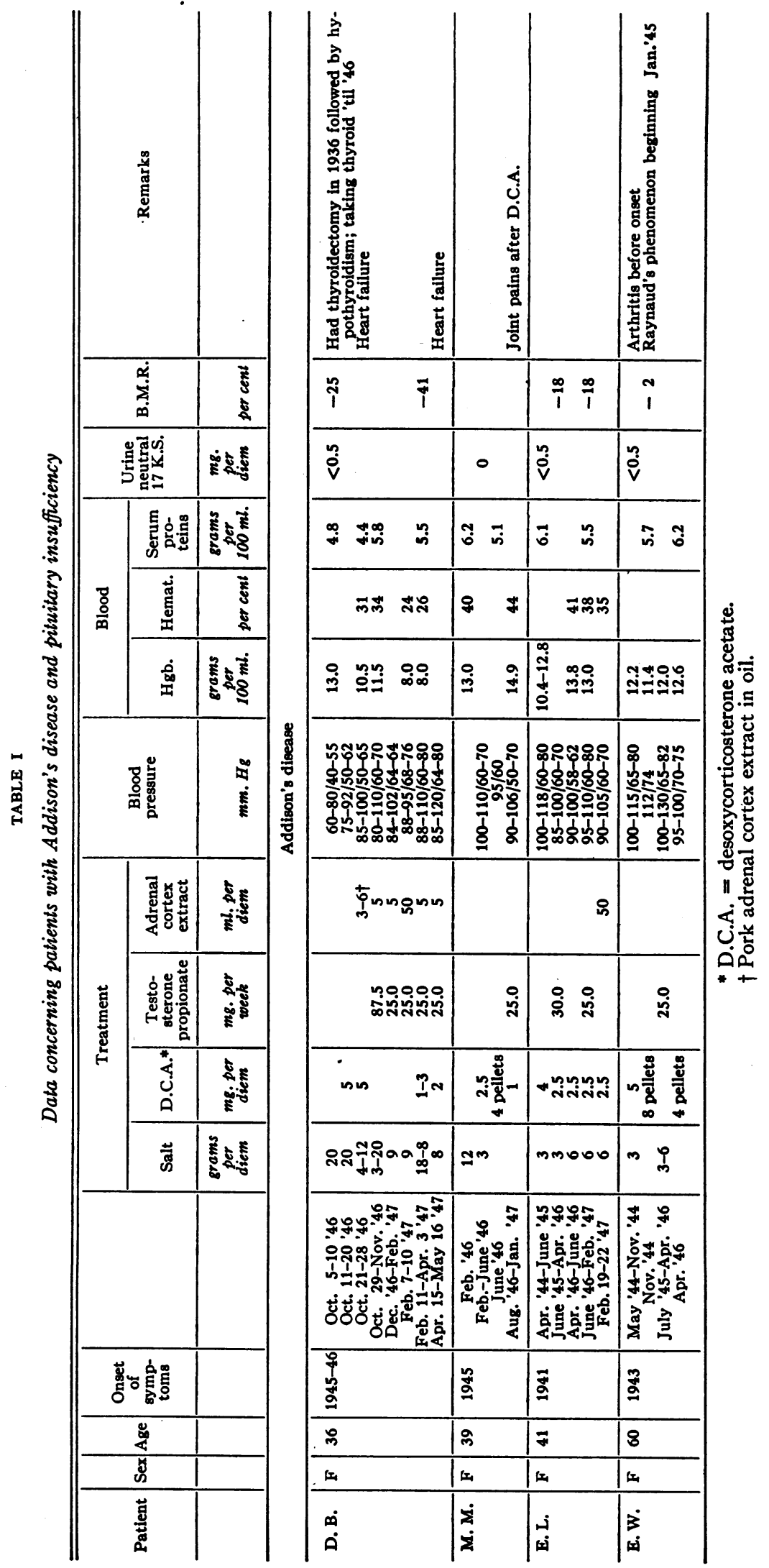



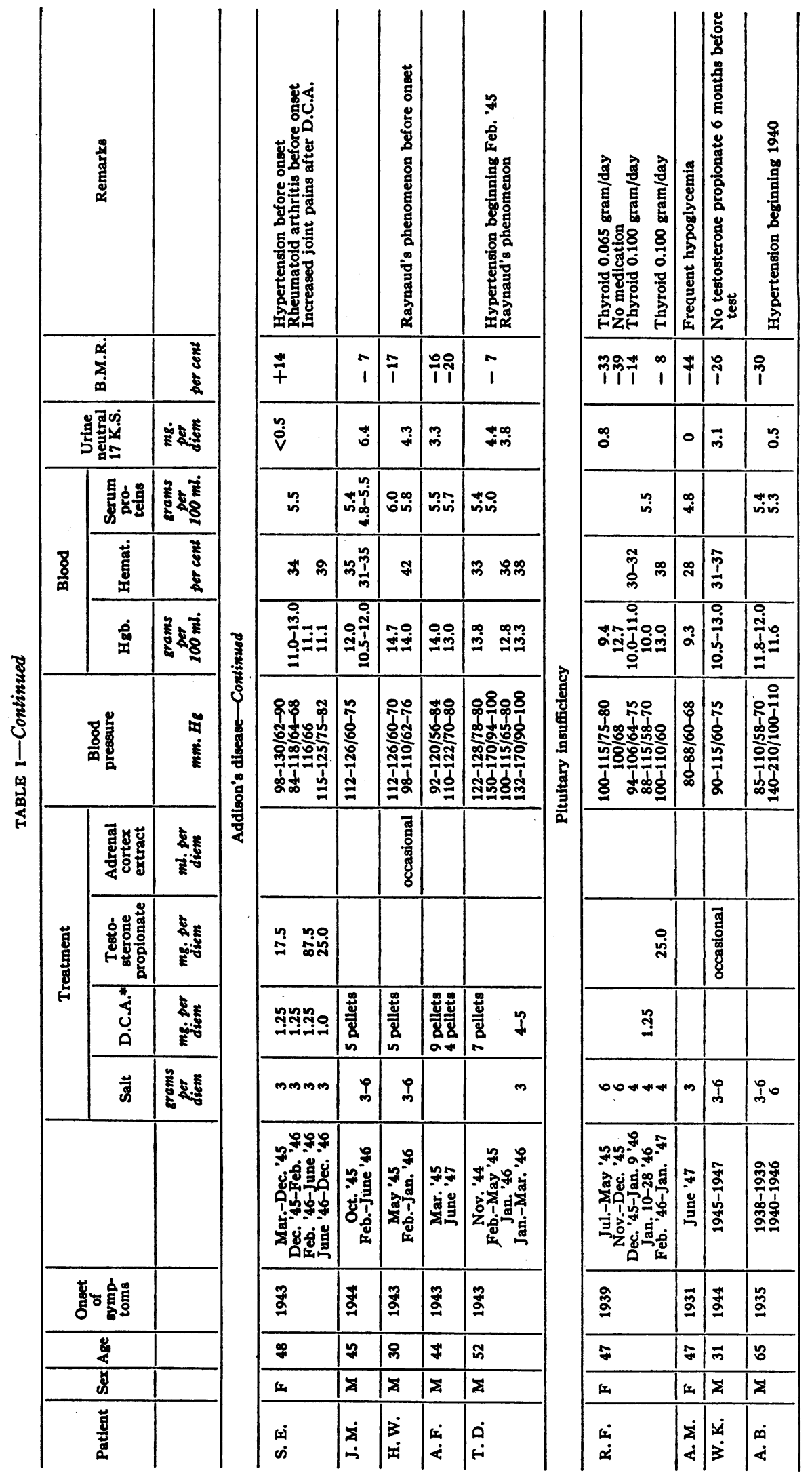


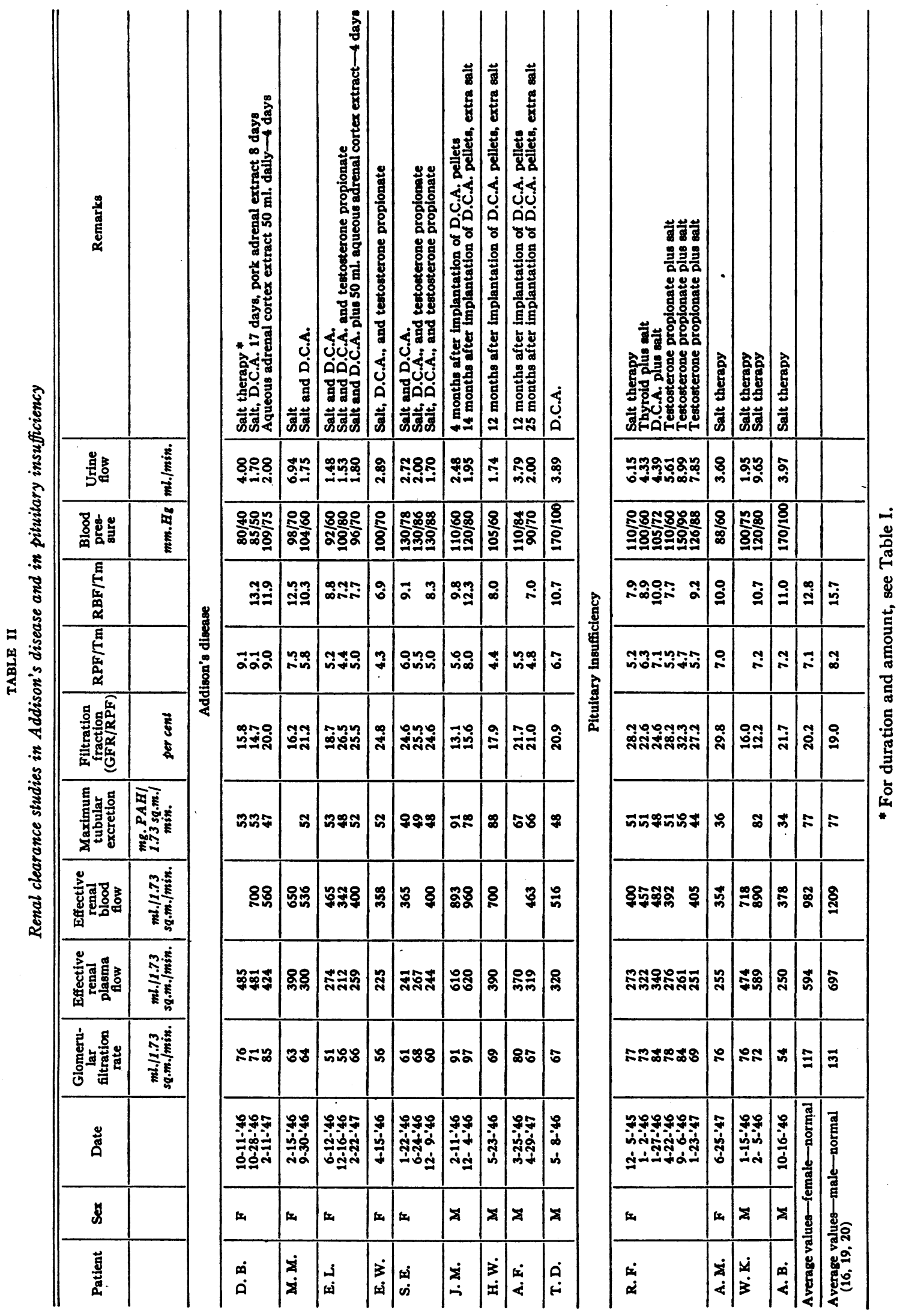


sion, yet tests enumerated above have continued to be abnormal and he develops symptoms of sodium chloride deficiency when not treated with salt or testosterone propionate.

All the patients were studied when in good clinical condition, it being our purpose to avoid the complicating factors present in crisis or shock. Observations were made while the patients were under basal conditions, i.e., about 14 hours after the previous meal. Several patients, who had a tendency to develop spontaneous hypoglycemia, were given $200 \mathrm{ml}$. of orange juice one hour before the test since it was found that this did not change the results.

Two patients with Addison's disease (D. B. and M. M.) and all those with hypopituitarism were studied first on salt alone. The other seven patients with Addison's disease had been treated with desoxycorticosterone acetate (D.C.A.) before studies were begun. After satisfactory observations had been made under either of the above conditions, treatment with other hormone preparations was superimposed when possible. We were thus able to study the influence of desoxycorticosterone acetate (D.C.A.), testosterone propionate, aqueous adrenal cortex extract, extract of pork adrenal cortex in oil, and desiccated thyroid, U.S.P.

Renal function studies were made by the multiple period technique advocated by Goldring et al. (15). Rates of glomerular filtration were determined as mannitol clearances (16). Effective renal plasma flow and maximum tubular excretory capacity were determined from para-amino-hippuric acid (P.A.H.) clearances at the proper plasma levels as outlined by Chasis et al. (17). Analyses were made upon plasma filtrates prepared according to Fujita and Iwatake (18) and on diluted aliquots of urine. Mannitol was determined according to the method of Smith, Finkelstein, and Smith (16). Para-amino-hippuric acid (P.A.H.) was determined according to the method of Bratton and Marshall as modified by Smith et al. (19). All results were corrected in proportion to surface area, the final figure being in terms of a surface area of 1.73 sq. meters. Values for these clearances obtained in our laboratory on normal persons are approximately the same as those published by Smith, Goldring, Chasis et al. $(17,20,21)$.

\section{RESULTS}

The results of all observations are recorded in Table II, and a typical test for each patient when either on sodium chloride alone or when receiving D.C.A. is illustrated in Figure 1.

Rates of glomerular filtration were below normal in all patients at all times. This is in agreement with the data published by Talbott $e t$ al. (2). Treatment with hormones resulted in little if any improvement above that found when salt was used in sufficient amounts to cause adequate improvement in the clinical condition and restoration of

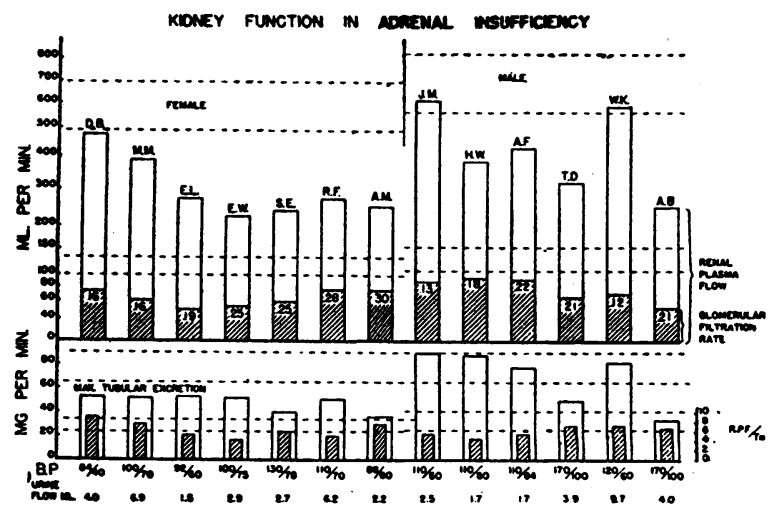

Fig. 1. Renal Clearance Studies in Addison's Disease and in Pituitary Insufficiency

Patients, D. B., M. M., R. F., A. M., W. K., and A. B., were receiving sodium chloride in sufficient amounts to control symptoms, serum electrolytes, etc. All other patients were receiving desoxycorticosterone acetate. Normal values for the various functions fall between the broken lines. The maximum tubular excretion is for P.A.H. The numbers appearing in the upper, crosshatched columns are the filtration fractions.

extracellular electrolytes, water and blood pressure (see D. B., M. M., and R. F., Table II). In A. F. there was a slight decrease between the observations made 12 months and 25 months after implantation of nine pellets of D.C.A. ${ }^{2}$ Decreased electrolyte retention between the two periods of observation was to be expected and can explain the decrease in glomerular filtration.

When extract of adrenal cortex was given in large amounts ( $50 \mathrm{ml}$. daily) there was perhaps slight increase of filtration but the values were still far below normal.

The filtration fraction

$$
\text { ( } \left.\frac{\text { Glomerular Filtration Rate }}{\text { Renal Plasma Flow }}\right)
$$

varied considerably at different times in the same subject and also from individual to individual. In general it was normal or high but in three instances it was exceptionally low. The variations cannot be explained without more control observations prior to the institution of hormonal therapy. In the two female patients with Addison's disease (D. B. and M. M.) who had previously been controlled with salt, the filtration

\footnotetext{
2 Two months after the last observation reported here the remnants of two of the nine pellets implanted 27 months previously were recovered.
} 
fraction increased after administration of adrenal cortical hormones which suggests that specific medication may have been a contributing factor.

The maximum excretory capacity of the tubular cells for para-amino hippuric acid (P.A.H.) showed the most interesting deviations from normal. It was low in all female patients and normal in all male patients with the exception of the two men, T. D. and A. B., who had hypertension. As both had had elevated blood pressures for more than a year, the decreased excretion of P.A.H. may have been a hypertensive phenomenon (19). In Patient T. D., hyperpiesa followed excessive treatment with desoxycorticosterone. In A. B. the etiology was not clear and it was present in spite of evidence of insufficiency of the anterior lobe of the pituitary and the adrenal cortex.

Testosterone propionate was given intramuscularly to several of the female patients (see Table I). S. E. received $25 \mathrm{mg}$. every other day for 20 weeks. At the end of this time a second series of observations showed no significant change from the controls. Treatment was then continued with $25 \mathrm{mg}$. per week for 24 weeks and again there was no improvement. Patient D. B. was given $25 \mathrm{mg}$. every other day for four weeks and then $25 \mathrm{mg}$. once a week without influencing the function studies. To test the possibility of causing improvement by giving small doses over a long period of time, Patient $\mathrm{R}$. F. was given $25 \mathrm{mg}$. weekly for over a year and $E$. L. the same dose for six and a half months but no change was observed in either case.

Admittedly the doses given the last two patients were rather small but . it was enough to cause marked improvement in their clinical condition. The amount of hormone given S. E. on the other hand should have been ample to bring out any potential effects.

Aqueous adrenal cortex extract was given to patients, D. B. and E. L., in doses of $50 \mathrm{ml}$. daily for three days, followed by administration of the extract during the tests, and no change was observed in the $T \mathrm{~m}$ for P.A.H. D. B. had received $5 \mathrm{ml}$. of extract daily for three months before the large amounts were given.

Thyroid substance likewise produced no change when given to one female patient, R. F., who had pituitary myxedema.
Effective renal blood flow was always reduced below normal. This was also true of the effective renal plasma flow except in two male patients who had moderate anemia (J. M. and W. K.). In the latter the effective renal plasma flow was within low normal values but the whole blood flow was well below normal. Similar findings have been reported in various anemias by Bradley and Bradley (22). Whether the patients were controlled on salt alone or receiving specific therapy seems to have made little if any difference in this function.

\section{DISCUSSION}

The distinctive features of the derangement of renal function found in these studies were (a) permanent decrease of renal blood flow and glomerular filtration rate in all patients and $(b)$ reduction of the maximum capacity of the tubules to excrete P.A.H. in all female patients. The consistent finding of decrease of renal blood flow and glomerular filtration rate regardless of the presence or absence of impairment on the part of the tubular cells to excrete P.A.H. is a point of considerable interest. The height of the blood pressure did not seem to be a factor as long as the patients were in good clinical condition. Indeed, comparatively high functional values were obtained at times even in the presence of low blood pressure (see D. B.). Hydration of the patients was always good so that decreased volume of the circulating blood was probably not responsible. While this has been found below normal in untreated adrenal insufficiency it is restored to normal by treatment with desoxycorticosterone or adrenal cortex extract $(23,24)$. As may be noted in Table II, low renal blood flow and glomerular filtration rates were obtained in our patients while receiving adequate treatment with these preparations. The several tests employed may indicate the status of various parts of the renal vasculature. Consideration of all the data compels us to postulate a reduction in the effective vascular bed in the kidneys with resulting decrease of renal plasma flow and concomitant reduction in the rate of glomerular filtration.

In those patients with Addison's disease whom we were able to study while on salt therapy alone, the ratios, R. B. F./Tm, were low normal and this fact may be interpreted as evidence against rela- 
tive ischemia of the functioning excretory tubular tissue of the kidneys (21). The Addisonian patients who had been under the influence of desoxycorticosterone acetate for long periods of time as well as all those with pituitary insufficiency were found to have a relatively greater reduction of renal blood flow than of their maximum ability to excrete P.A.H. (low ratio of R.B.F./Tm) or relative ischemia of the tubular tissues (21). It is uncertain whether this latter finding was the result of disease or was due to treatment.

Information on whether specific therapy affects the filtration apparatus should be afforded by examination of the filtration fraction. Talbott (2) found low filtration fractions in two cases of Addison's disease treated with sodium chloride alone, and this agrees with our observations in two cases studied under similar conditions. All but one of our nine Addisonian patients had normal or slightly elevated filtration fractions after treatment with D.C.A. or aqueous adrenal extract. Of four pan-hypopituitary patients in our series all but one had high filtration fractions. This was true also in two cases studied by Talbott. From the evidence at hand it appears that the patient with Addison's disease prior to specific treatment will show a low filtration fraction in contradistinction to pan-hypopituitarism where the untreated subject may be expected to have a high filtration fraction.

Unusual sensitivity of the blood vessels in patients with Addison's disease to vasoconstrictor as well as vasodilator influences has been reported $(25,26)$. Roth, Robinson and Wilder (25) found that the unusual hyperreactivity of the Addisonian patient to the constrictor influence of cold was increased by treatment with desoxycorticosterone acetate. From the data available it seems more than probable that treatment with this steroid exerted a vasoconstrictor influence on the vascular bed of the kidneys in our patients. The unexplainable variations in general obtained in some of our patients, especially those with panhypopituitarism, are probably due to opposing influences and trophic factors which are not understood.

The failure of any of the functions to improve with the medication given may have been due to several causes. The dose of adrenal cortex hormone may have been insufficient or not given for a long enough time, in spite of the prompt and adequate restoration which such doses cause in other functions $(27,28)$. Irreversible structural or functional changes may have taken place. Whether or not histological changes accompany functional changes in kidneys in adrenal insufficiency has been the subject of considerable controversy ( 8 to $10,29,30)$. It is possible that this may be clarified to some extent if the sex of the patients or animals studied is taken into consideration. Gaunt (31) was unable to correct the defect in water diuresis in adrenalectomized rats, even when adequate hormonal therapy was instituted in less than a week after adrenalectomy.

Finally, the factors responsible for maintenance of the functions mentioned may not have been present in any of the preparations given. The failure of testosterone propionate to restore the $\mathrm{Tm} /$ P.A.H. in the female patients is of special interest. The hormonal factors which help maintain this function in the males are undoubtedly made by the testis, but cannot be replaced by testosterone propionate.

\section{SUM MARY}

1. Studies on glomerular filtration rate, renal plasma flow and maximum excretory capacity are reported on 13 patients with adrenal insufficiency.

2. Maximum excretory capacity was reduced in female patients and was not affected by hormone therapy.

3. Filtration rates were reduced and it is postulated that absolute reduction at least in the long standing, well controlled Addisonian, is secondary to reduction in renal plasma flow.

4. Changes in the renal blood flow are discussed with regard to the disease per se and to hormonal therapy.

\section{BIBLIOGRAPHY}

1. Smith, T. W., A case of Addison's disease, fatal by suppression of urine. Guy's Hosp. Rep., 1897, 54, 229.

2. Talbott, J. H., Pecora, L. J., Melville, R. S., and Consolazio, W. V., Renal function in patients with Addison's disease and in patients with adrenal insufficiency secondary to pituitary pan-hypofunction. J. Clin. Invest., 1942, 21, 107.

3. Selye, H., Effect of hypophysectomy on morphological appearance of kidney and on renotrophic action of steroid hormones. J. Urol., 1941, 46, 110. 
4. Kochakian, C. D., A comparison of the renotrophic with the androgenic activity of various steroids. Am. J. Physiol., 1944, 142, 315.

5. Welsh, C. A., Rosenthal, A., Duncan, M. T., and Taylor, H. C., Jr., The effects of testosterone propionate on renal function in the dog, as measured by the creatinine and diodrast clearance and diodrast Tm. Am. J. Physiol., 1942, 137, 338.

6. Klopp, C., Young, N. F., and Taylor, H. C., Jr., The effects of testosterone and testosterone propionate on renal functions in man. J. Clin. Invest., 1945, 24, 189.

7. Bassett, S. H., Keutmann, E. H., and Kochakian, C. D., Effects of injections of testosterone propionate on a male subject with nephrotic syndrome. J. Clin. Endocrinol., 1943, 3, 400.

8. Barker, N. W., The pathologic anatomy in 28 cases of Addison's disease. Arch. Path., 1929, 8, 432.

9. Mainzer, F., Utber die Störung der "Nierenfunktion" bei Addison'scher Krankheit Schweiz. Med. Wchnschr., 1937, 67, 31.

10. Simpson, S. L., and Korenchevsky, V., Histological changes in the kidneys of adrenalectomized rats. J. Path. \& Bact., 1935, 40, 483.

11. Cutler, H. H., Power, M. H., and Wilder, R. M., Concentrations of sodium and potassium in urine and blood; their diagnostic significance in adrenal insufficiency. J. A. M. A., 1938, 111, 117.

12. Talbot, N. B., Berman, R. A., and MacLachlan, E. A., Elimination of errors in the colorimetric assay of neutral urinary 17 -ketosteroids by means of a color correction equation. J. Biol. Chem., 1942, 143, 211.

13. Means, J. H., Hertz, S., and Lerman, J., The pituitary type of myxedema or Simmond's disease masquerading as myxedema. Tr. A. Am. Physicians, $1940,55,32$.

14. Fraser, R. W., Albright, F., and Smith, P. H., Value of glucose tolerance test, insulin tolerance test, and glucose-insulin tolerance test in diagnosis of endocrinologic disorders of glucose metabolism. J. Clin. Endocrinol., 1941, 1, 297.

15. Goldring, W., Chasis, H., Ranges, H. A., and Smith, H. W., Relations of effective renal blood flow and glomerular filtration to tubular excretory mass in normal man. J. Clin. Invest., 1940, 19, 739.

16. Smith, W. W., Finkelstein, N., and Smith, H. W., Renal excretion of hexitols (sorbitol, mannitol, and dulcitol) and their derivatives (sorbiton, ismannide and sorbide) and of endogenous creatinine-like chromogen in dog and man. J. Biol. Chem., 1940, 135, 231.

17. Chasis, H., Redish, J., Goldring, W., Ranges, H. A., and Smith, H. W., The use of sodium p-amino hipppurate for the functional evaluation of the human kidney. J. Clin. Invest., 1945, 24, 583.
18. Fujita, A., and Iwatake, D., Bestimmung des echten Blutzuckers ohne Hefe. Biochem. Ztschr., 1931, 242, 43.

19. Smith, H. W., Finkelstein, N., Aliminosa, L., Crawford, B., and Graber, M., The renal clearances of substituted hippuric acid derivatives and other aromatic acids in $\operatorname{dog}$ and man. J. Clin. Invest., 1945, 24, 338.

20. Smith, H. W., Golding, W., Chasis, H., Ranges, H. A., and Bradley, S. E., William Henry Welch Lectures II, The application of saturation methods to the study of glomerular and tubular function in the human kidney. J. Mt. Sinai Hosp., 1943, 10, 59.

21. Goldring, W., and Chasis, H., Hypertension and Hypertensive Disease. New York, The Commonwealth Fund, 1944, pp. 56 and 66.

22. Bradley, S. E., and Bradley, G. P., Renal function during chronic anemia in man. Blood, J. Hemat., 1947, 2, 192.

23. Thorn, G. W., Howard, R. P., and Emerson, K. J., Treatment of Addison's disease with desoxycorticosterone acetate, synthetic adrenal cortical hormone (preliminary report). J. Clin. Invest., 1939, 18, 449.

24. Ferrebee, J. W., Ragan, C., Atchley, D. W., and Loeb, R. F., Desoxycorticosterone esters. Certain effects in the treatment of Addison's disease. J. A. M. A., 1939, 113, 1725.

25. Roth, G. M., Robinson, F. J., and Wilder, R. M., Changes of the systolic and diastolic blood pressure and response of blood pressure to the cold pressor test among patients suffering from Addison's disease-during treatment with desoxycorticosterone acetate. Proc. Staff Meet. Mayo Clin., 1943, 18, 450.

26. Perera, G. A., Acetyl-beta-methylcholine in Addison's disease. J. A. M. A., 1945, 128, 1018.

27. Thorn, G. W., Garbutt, H. R., Hitchcock, F. A., and Hartman, F. A., The effect of cortin on the sodium, potassium, chloride, inorganic phosphorus and total nitrogen balance in normal subjects and in patients with Addison's diseaese. Endocrinology, 1937, 21, 202.

28. Lewis, R. A., Kuhlman, D., Delbus, C., Koepf, G. F., and Thorn, G. W., The effect of adrenal cortex extract on carbohydrate metabolism. Endocrinology, 1940, 27, 971.

29. Guttman, P. H., Addison's disease. A statistical analysis of 566 cases and a study of the pathology. Arch. Path., 1930, 10, 742.

30. Gersh, I., and Grollman, A., Kidney function in adrenal cortical insufficiency, Am. J. Physiol., 1939, 125, 66.

31. Gaunt, R., Animal experiments relating to water diuresis tests for adrenal insufficiency. $J$. Clin. Endocrinol., 1946, 6, 595. 